Universidade do Estado de Santa Catarina

Centro de Educação Superior do Alto Vale do Itajaí

\title{
A CONTABILIDADE DE CUSTOS NAS UNIVERSIDADES DA ESPANHA: UMA ANÁLISE DA ESTRUTURA DOS PLANOS DE ENSINO DA DISCIPLINA NA GRADUAÇÃO
}

\author{
Ilaci Pavesi ${ }^{1}$, Altair Borgerti ${ }^{1}$ \\ ${ }^{1}$ Universidade Federal de Santa Catarina \\ e-mail de contato: ilacip@terra.com.br
}

\section{Resumo}

Com o propósito de identificar o perfil da disciplina de contabilidade de custos nos cursos de graduação oferecidos nas universidades espanholas, este artigo teve por objetivo pesquisar os planos de ensino da disciplina que abordam o conteúdo de contabilidade de custos nos cursos de graduação em Contabilidade e Finanças. A pesquisa é do tipo documental. A técnica utilizada para coleta de dados foi por análise de dados secundários, compostos pelos planos de ensino com o conteúdo de Contabilidade de Custos das Universidades da Espanha. No que concerne à abordagem do problema, foram utilizadas metodologias de natureza qualitativa e quantitativa. A amostra contempla 10 universidades públicas e 14 planos de ensino. De modo geral os resultados mostraram que: (i) a disciplina de custos possui 6 créditos; (ii) os conteúdos programáticos tratam dos temas: Conceptos Básicos/Fundamentales de Costes, Costes por Procesos, Costes Estándares, Los Centros de Costes/Centros o areas de Responsabilidad, Los Sistemas de Costes Basados en las Actividades (ABC), El Coste de Absorción e Asignación de Costes;(iii) os alunos são avaliados por prova final e parciais, e; (iv) as bibliografias adotadas tem como principais autores: Horngren, Forster e Datar, com a obra Contabilidad de Costes. Conclui-se que há certa homogeneidade no que diz respeito à estrutura dos planos de ensino das universidades pesquisadas.

Palavras-chave: Contabilidade de Custos. Planos de Ensino. Universidades da Espanha.

\section{THE COST ACCOUNTING AT UNIVERSITIES IN SPAIN: ANANALYSIS IN STRUCTURE OF THE SYLLABUS OF THE SUBJECTS AT GRADUATION}

\begin{abstract}
Aiming to identify the profile of Cost Accounting subjects in graduation courses offered at Spanish universities, this essay has the objective to verify the syllabus of the subject which approach the cost accounting content in the graduation courses of Accounting and Finance, with the objective of identity its basic structure, objectives, methodologies, evaluation process, content, bibliographies. This essay is descriptive, with qualitative and quantitative approach. As for the technical proceedings, the strategy of the research is documental. The used technique for the data collection was analysis of secondary data, based on the syllabus with the content of Cost Accounting of Spanish universities. For the problem approach it was used qualitative and quantitative methodologies. In general, the results showed that: (i) the cost and management subject has 6 credits; (ii) the content of the subject deal with: Conceptos Básicos/Fundamentales de Costes, followed by Costes por Procesos, Costes Estándares, Los Centros de Costes/Centros o areas de Responsabilidad, Los Sistemas de Costes Basadosenlas Actividades ABC), El Coste Completo o de Absorción e Asignación de Costes. Also topics such as: Presupuestos, Costes Variables y Costes Fijos Costes Directos y Costes Indirectos and El Análisis Coste-VolumenBeneficio (CBV); (iii) students are evaluated with a final test, partial test, individual jobs,
\end{abstract}


Universidade do Estado de Santa Catarina

Centro de Educação Superior do Alto Vale do Itajaí

exercises and group work; (iv) the references used are from main authors such as: Horngren, Forster and Datar, and his job named Contabilidad de Costes. It is observed a certain homogeneity regarding the structure of the syllabus among the researched universities.

Keywords: Cost Accounting. Syllabus. Spanish Universities.

\section{Introdução}

A linguagem contábil é universal, e, com a globalização dos negócios tornou-se importante para todos os países (IUDÍCIBUS, 2010). Entre vários assuntos, a formação dos contadores tem sido uma preocupação constante dos organismos internacionais de contabilidade como o International Federation of Accountants (IFAC) e o International Accounting Standards Board (IASB), bem como da Organização das Nações Unidas (ONU), por meio de setores como o Intergovernmental Working Group of Experts on International Standards of Accounting and Reporting (ISAR) e United Nations Conference on Trade and Developmen (UNCTAD)

As exigências profissionais e a rapidez das transformações e inovações científicas e tecnológicas requerem uma constante atualização e adequação do currículo. Neste sentido, Mendivil (2002) aponta que as instituições educacionais estrangeiras e brasileiras iniciaram um processo de adaptação às pressões da globalização através da internacionalização dos currículos e de atividades, ou seja, a internacionalização do ensino contábil. Estudos de Riccio e Sakata (2004) indicam que as instituições de ensino contábil dos diversos países são estimuladas a adequar-se às mudanças provocadas pela globalização e pela consequente necessidade de harmonização de conceitos e práticas. Cabe às instituições de ensino esse papel, ou seja, o planejamento dos conteúdos. Para Libâneo (1994), plano de ensino é a previsão dos objetivos e tarefas do trabalho docente para o ano ou semestre. Também é um documento mais elaborado, dividido por unidades sequenciais, no qual aparecem objetivos específicos, conteúdos e desenvolvimento metodológicos.

$\mathrm{Na}$ Espanha, identificam-se esforços por parte governo para que os currículos se assemelhem ao Currículo Mundial. A exemplo, o Tratado de Bolonha é um documento conjunto assinado pelos ministros da educação de 29 países europeus, com o intuito de estabelecer uma área europeia de ensino superior a partir do comprometimento dos países signatários em promover reformas de seus sistemas de ensino, e proporcionar uniformidade no processo de ensino superior (Rosa, 2012).

Em 1988, no $900^{\circ}$ aniversário da universidade mais antiga da Europa, a Universidade de Bolonha, na Itália, foi assinada pelos reitores das universidades europeias a Magna Charta Universitatu. Nela consideram que o futuro da humanidade, neste fim de milénio, depende do desenvolvimento cultural, científico e técnico. São as universidades que forjam este saber. Corrobora Borges (2013) neste sentido, ao afirmar que o Processo de Bolonha consiste nas atividades desenvolvidas a partir da Declaração de Bolonha assinada em 1999, voltadas para a concretização da reforma dos sistemas de ensino superior europeus, decidiram pela construção da Área Europeia de Ensino Superior até 2010.

Uma das áreas de formação do contador que ganha destaque neste cenário é a Contabilidade de Custos, devido ao seu importante papel para o processo de tomada de decisões gerenciais. O Módulo de Contabilidade Gerencial constante no Currículo Mundial tem o objetivo de gerar informações contábeis capazes de facilitar decisões gerenciais em todos os níveis, nos seus esforços para alocar de forma eficiente e eficaz recursos econômicos, humanos e financeiros escassos da organização (UNCTAD, 2003). Neste sentido, corrobora Crepaldi (2008) ao afirmar que o objetivo da contabilidade de Custos é fornecer instrumentos aos administradores de empresas que os auxiliem em suas funções gerenciais. 
Diante deste contexto formulou-se o seguinte problema de pesquisa: qual o perfil da disciplina de contabilidade de custos nos cursos de graduação que formam o profissional contábil nas universidades públicas da Espanha? O objetivo deste trabalho é identificar o perfil da disciplina de custos nos cursos de graduação que se propõem a formar o profissional contábil nas universidades públicas espanholas.

Para responder à questão de pesquisa, foram investigados os planos de ensino das disciplinas que abordam o conteúdo de contabilidade de custos/contabilidade gerencial nos cursos de graduação em Finanças e Contabilidade das universidades espanholas públicas com o propósito de identificar o que, como, quando e de que forma, com quais métodos se ensinam, quais os métodos de avaliação, quais bibliografias são mais utilizadas para o ensino destas disciplinas na Espanha. $\mathrm{O}$ estudo tem como justificativa o conhecimento das melhores práticas em países mais desenvolvidos e que já adotaram as recomendações de organismos mundiais. Essa prática é conhecida como Benchmarking que, conforme Andersen, (1999) consiste em uma medida de referência, reconhecida como o padrão de excelência em determinados processos de negócios. Para Gariba Júnior (2005), benchmarking é em essência, um processo comparativo de identificação, compreensão e adaptação de boas práticas de outras organizações consideradas como as melhores, com a finalidade de introduzir melhorias na instituição e tentar levá-la ao nível daquelas concorrentes.

Este estudo está dividido em 4 seções, sendo a primeira a revisão da literatura, Em seguida, a metodologia aplicada à pesquisa e a seleção da amostra, os resultados da pesquisa e as conclusões do estudo.

\section{Revisão da literatura}

Nesta seção será abordado o funcionamento do sistema universitário na Espanha, a disciplina de contabilidade de custos nos seus cursos de graduaação, estudos anteriores e por último a estrutura dos planos de ensino.

\subsection{O Sistema universitário na Espanha}

A origem da universidade espanhola remonta ao princípio do século XIII quando nos reinos de Castilla e León fundam-se as primeiras instituições universitárias vinculadas às escolas catedráticas de Valencia, entre 1208 e 1214, e Salamanca em 1218. A verdadeira proliferação de centros universitários na Espanha coincide com o processo de descentralização estatal que se produz com a aprovação da Constituição de 1978 e por uma ampla demanda social de acesso aos estudos superiores. Assim, em 1984, a Espanha contava com 34 universidades e 700.000 estudantes e em 2013 totalizam 79 universidades com 1.582.714 (MECD, 2013).

De acordo com o MECD (2013) e Fundación para la proyección internacional de las universidades españolas (2013), há três tipos de universidades na Espanha: pública, privada e não presencial. Os títulos que elas oferecem podem ser oficiais e não oficiais, também chamados títulos próprios. Os títulos oficiais estão adaptados ao Espaço Europeu de Educação Superior (EEES) e tem validade oficial nos 27 países que compõem a União Europeia e são homologáveis/convalidáveis em outros países como os da América Latina, Ásia, África, etc., o que não ocorre com os títulos não oficiais.

Os títulos são avaliados unicamente pela mesma universidade pública ou privada que os emite, não pelo governo, e seu valor dependerá de sua aceitação no mercado de trabalho. Os títulos oficiais são denominados de Graduação Oficial, Mestrado Oficial e Doutorado e são estabelecidos pelo governo; enquanto os títulos próprios são denominados de Graduação não oficial (carreiras não oficiais), Magister ou Mestrado não oficial, Especialista e Expert. 
Os títulos oficiais são os adaptados ao EEES e são compostos por três ciclos: Graduação, Mestrado e Doutorado. Tanto o título de Graduação como o de Mestrado estão vinculados às seguintes áreas de conhecimento: Artes e Humanidades, Ciências, Ciências da Saúde, Ciências Sociais e Jurídicas e Engenharia e Arquitetura.

Figura 1 - Sistema Universitário da Espanha

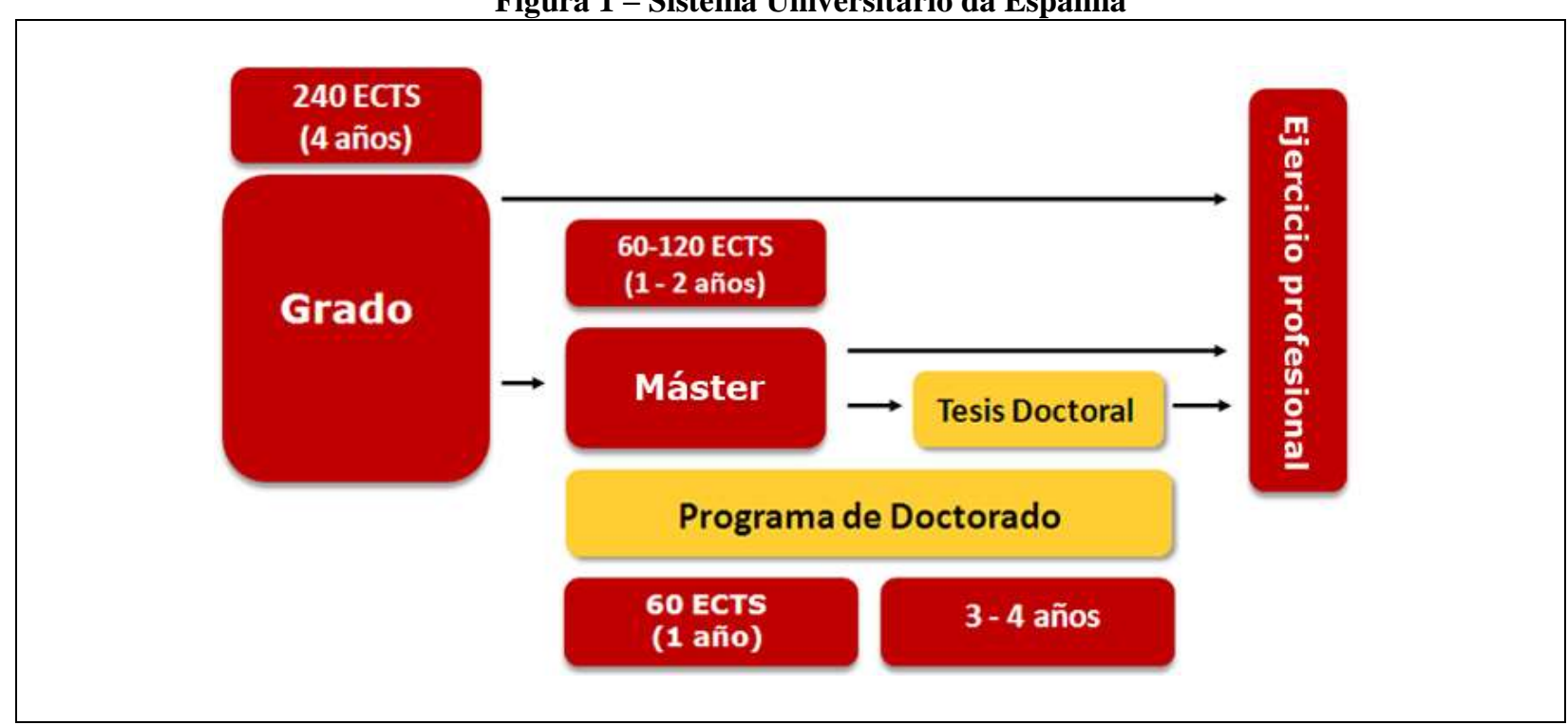

Fonte: (MECD-Ministério de Educação, Cultura e Desportes da Espanha, 2013)

Os créditos European Credit Transfer System (ECTS) são o padrão adotado por todas as universidades do EEES e garantem a convergência dos diferentes sistemas europeus de educação superior. Os créditos se baseiam no trabalho pessoal do estudante: horas letivas de estudo,elaboração de trabalhos e práticas. Um crédito ECTS equivale a 25 horas de trabalho do estudante.

A Graduação é o primeiro ciclo do ensino terciário e objeto deste estudo, tem uma duração de 240 créditos ECTS, divididos em quatro anos acadêmicos (incluindo o Trabalho de Final de Graduação). O título de Graduação está estruturado da seguinte maneira: disciplinas (assignaturas) de formação básica, disciplinas obrigatórias, disciplinas optativas, práticas externas, trabalho final de graduação e reconhecimento por atividades culturais.

2.1.1 A disciplina de Contabilidade de Custos nos cursos de graduação das universidades da Espanha

Assim como no Brasil, o ensino de custos e sua estrutura curricular, na Espanha se revestem de diferentes nomenclaturas. Nas universidades pesquisadas foram encontradas as seguintes nomenclaturas: Contabilidad de Costes, Contabilidad de Gestión, Gestión de Costes, Control Directivo e Contabilidad y Control de Gestión. Na Espanha, a Contabilidade de Custos também é conhecida com a nomemclatura Contabilidade Gerencial.

Carrillo (2011) pesquisou a disciplina de Contabilidade de Custos/ Contabilidade Gerencial ofertadas nos cursos de graduação das universidades públicas da Espanha, concluindo que o número total de disciplinas relacionadas a essas, somam 164, distribuídas por diversos cursos de graduação que o autor agrupou por similaridade: (i) Graduação em Administração e Direção de Empresas (GADE) ou denominação similar; (ii) Graduação em Finanças e Contabilidade (FICO) ou denominação similar, onde inclui os cursos de graduação em Contabilidade e Finanças; Comércio; Ciências Empresariais; Consultoria e Gestão da Informação; Finanças; Finanças, 
Bancos e Seguros; Finanças e Contabilidade e Gestão de Pequenas e Médias Empresas; (iii) Graduação em Turismo; (iv) Graduação em Economia; (v) Graduação em Marketing e Investigação de Mercados; (vi) Outras Graduações: Estatística e Empresa; Tributação e Administração Pública; Gestão Pública; Informática, Negócios Internacionais.

\subsection{Estudos anteriores}

Alguns estudos envolvendo a contabilidade de custos ou contabilidade gerencial na Espanha merecem destaque. Como o de Rosa, Lunkes, Pfitscher e Soares (2012) que avaliou as informações contidas em currículos e publicações científicas para identificar a legitimidade cognitiva da disciplina de contabilidade gerencial na Espanha e concluíram que a formação de novos doutores está em estágio de consolidação.

Neste sentido também Escobar Perez, Lobo Gallardo e Peña (2005) realizaram uma investigação empírica em contabilidade de gestão na Espanha através de análises nas publicações espanholas.

Carrillo (2011) estudou os currículos dos cursos de graduação que continham a disciplina de contabilidade de custos ou contabilidade gerencial nos diversos cursos de graduação das universidades públicas da Espanha. O estudo foi apresentado durante o II Encuentro de docentes de contabilidad de costes y control de gestión. Seus achados demonstram de forma geral as características como as competências e finalidades, além dos conteúdos e materiais bibliográficos utilizados na disciplina, porém apenas de forma qualitativa e abrangeu todas as graduações que ofertam a disciplina. Enquanto a proposta da presente pesquisa objetiva traçar também, de forma qualitativa o perfil da disciplina e apenas nas graduações que formam o profissional de contabilidade.

Quanto aos planos de ensino de contabilidade de custos ou gerencial no Brasil, diversos estudos relacionam o currículo brasileiro ao Currículo Mundial proposto pela UNCTAD/ISAR/ONU como o de Magalhães e Andrade (2006), o de Erfurt, (2009) e os estudos de Riccio e Sakata (2004).

Também estudos no Brasil referentes ao ensino da contabilidade de custos: Raup (2009; Nossa (1998); Itoze Mineiro (2005); Pinto, Silveira e Domingues (2008). Sobre a disciplina de custos citam-se os trabalhos de Gallon, Oro, Eidt e Domingues (2005) e Godoy, Silva e Nakamura (2004).

\subsection{Estrutura dos planos de ensino}

Para Libâneo (1992), planejamento de ensino é um processo de racionalização, organização e coordenação da ação docente, articulando a atividade escolar e a problemática do contexto social. De acordo com Schmitz (1985) são elementos fundamentais, integrantes de qualquer plano de ensino: objetivos, conteúdos, linha de ação ou estratégia e avaliação.

Os objetivos são a determinação clara e descritiva do que se pretende. Constituem a especificação do que se espera como resultado. O conteúdo é o que dá concretude aos objetivos, é algo a ser realizado, aprendido, executado (SCHMITZ, 1985). Refere-se à organização do conhecimento em si (PILETTI, 1990). Já a estratégia ou linha de ação, resume o modo como se procederá para trabalhar os conteúdos e alcançar os objetivos (SCHMITZ, 1985).

A seguir, o elemento curricular denominado "Avaliação" da estrutura dos planos de ensino é apresentado segundo uma visão comparativa de diversos autores.

\subsubsection{Avaliação}


Avaliação, segundo Schmitz (1985), é a validação de toda a atividade e dos resultados, é um processo contínuo, cumulativo, descritivo e global de acompanhamento da aprendizagem. De acordo com Piletti (1990), avaliação é um processo contínuo que visa interpretar os conhecimentos habilidades e atitudes do aluno. Corrobora Demo (2003), afirmando que a avaliação é um procedimento fundamental, indispensável e permanente. Não é um fim, mas um meio que permite verificar até que ponto os objetivos estão sendo alcançados (BONNIOL, 2001).

Neste sentido, Gil (2002) lista os requisitos necessários para que a avaliação seja adequada ao nível superior: deve estar vinculada aos objetivos da aprendizagem; (ii) deve ser contínua; (iii) deve ser objetiva e (iv) deve abranger os diversos domínios da aprendizagem.

A avaliação é um elemento curricular que abrange aspectos distintos na visão de diversos autores, conforme apresentado no Quadro I.

\begin{tabular}{|c|c|c|c|c|}
\hline Luckesi & Gimeno & Hoffmann & Perrenoud & Vasconcellos \\
\hline $\begin{array}{l}\text { Juízo de valor sobre } \\
\text { dados relevantes } \\
\text { objetivando uma } \\
\text { tomada de decisão. } \\
\text { Diagnostica: } \\
\checkmark \text { Qualidade de } \\
\text { resultados, } \\
\checkmark \text { Implica } \\
\text { retomada do } \\
\text { curso da ação, } \\
\checkmark \text { Instrumento } \\
\text { auxiliar da } \\
\text { aprendizagem. }\end{array}$ & $\begin{array}{l}\text { Expressão de um } \\
\text { juízo de valor por } \\
\text { parte do professor. } \\
\text { Pressupõe tomada } \\
\text { de decisão e apoia- } \\
\text { se em indícios e } \\
\text { evidências. }\end{array}$ & $\begin{array}{l}\text { É dialógica e } \\
\text { interativa. Promove } \\
\text { o indivíduo moral e } \\
\text { intelectualmente } \\
\text { tornando-o crítico e } \\
\text { participativo. } \\
\text { Meio de } \\
\text { acompanhamento do } \\
\text { processo ensino- } \\
\text { aprendizagem. }\end{array}$ & $\begin{array}{l}\text { Privilegia um modo } \\
\text { de estar em aula e } \\
\text { no mundo, valoriza } \\
\text { formas e normas de } \\
\text { excelência, define } \\
\text { um aluno modelo, } \\
\text { aplicado e dócil para } \\
\text { uns, imaginativo e } \\
\text { autônomo para } \\
\text { outros. } \\
\text { Avalia-se sempre } \\
\text { para o agir. }\end{array}$ & 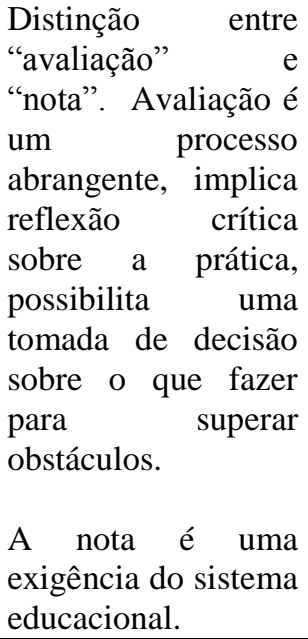 \\
\hline
\end{tabular}

Fonte: (Adaptado de GARIBA JUNIOR, 2005)

É recomendável que o docente utilize diversos instrumentos e/ou procedimentos. Numa avaliação que privilegia o processo, avaliar lançando mão de um único instrumento não é apropriado (DEMO, 2003, p.29). É por meio da avaliação que, segundo Lück, (2002) pode-se demonstrar que a ação produz alguma diferença quanto ao desenvolvimento dos alunos.

\section{Metodologia}

O presente trabalho caracteriza-se, do ponto de vista de seus objetivos, como uma pesquisa descritiva. Segundo Gil (2002, p. 42), as pesquisas que possuem como objetivo principal a descrição das características de determinado fenômeno ou população, ou que estabelecem relações entre variáveis podem ser denominadas de pesquisas descritivas. Quanto aos procedimentos técnicos, a estratégia de pesquisa é do tipo documental. Para Gil (2002) considera-se documental quando a pesquisa é elaborada a partir de materiais que não receberam tratamento analítico A técnica utilizada para coleta de dados foi por análise de dados secundários, compostos pelos planos de ensino com o conteúdo de Contabilidade de Custos das Universidades da Espanha, disponibilizados em seus sites institucionais. No que concerne à abordagem do problema, são utilizadas metodologias de natureza qualitativa e quantitativa. 
A Espanha possui 79 (setenta e nove) universidades, das quais 47 (quarenta e sete) são públicas e 32 (trinta e duas) privadas e da igreja católica (MECD, 2013). As Universidades que compõe a amostra estão representadas na Tabela 1:

Tabela 1 - Universidades selecionadas

\begin{tabular}{c|l}
\hline No. & Universidade \\
\hline 1 & Universidad de Granada \\
\hline 2 & Universidad de Almería \\
\hline 3 & Universidad Carlos III de Madrid \\
\hline 4 & ETEA - Institución Universitaria de la Compañía de Jesús \\
\hline 5 & Universidad de Cádiz \\
\hline 6 & Universidad de la Laguna \\
\hline 7 & Universitat de Girona \\
\hline 8 & Universitat de València \\
\hline 9 & Universidad de Sevilla \\
\hline 10 & Universidad de Oviedo \\
\hline &
\end{tabular}

Foram selecionadas como amostra 10 universidades federais que ofertam o curso de Graduação em Finanças e Contabillidade (Grado en Finanzas y Contabilidad/ Grado em Contabilidad y Finanzas) e que contém as disciplinas de Contabilidade de Custos (Contabilidad de Costes/ Contabilidad de Gestión) em seu plano de ensino, sendo que nas Universidades de Granada, Almería, ETEA, Sevilla e Oviedo foram analisadas 2 planos de ensino com nomenclaturas distintas, totalizando 14 planos de ensino com validade para os anos de 2012 e/ou 2013, conforme acesso eletrônico aos sites das respectivas universidades ou solicitação ao coordenador do curso. O período de dos dados ocorreu nos meses de julho a setembro de 2013.

\section{Resultados}

Dos 14 planos de ensino analisados, a quantidade de créditos da disciplina vale 6 ECTS para 12 planos e uma universidade apresentou a disciplina com validade de 9 créditos. A Metodologia de ensino mais utilizada é a aula expositiva, constante em $100 \%$ dos planos analisados, seguido das aulas práticas/laboratório, citado por 10. Os trabalhos individuais, trabalhos em grupo, estudo de casos, foram citados em 6 planos. Já os testes de auto avaliação foram citados por 5 planos de ensino. Estes testes são realizados em ambiente virtual e tem prazo definido após as aulas para serem feitos. Resolução de Exercícios aparecem em 4 planos, Seminários em 3, e Revisão de bibliografias de um tema com apresentação de resumo em 2 planos de ensino.

\subsection{Estrutura dos Planos de Ensino}

Os Planos de Ensino pesquisados apresentam a estrutura demonstrada na Tabela 2:

Tabela 2: Estrutura dos planos de ensino

\begin{tabular}{l|c|c}
\hline Elemento & N. de Menções & (\%) \\
\hline Objetivo da disciplina & 14 & 100,00 \\
\hline Competências & 14 & 100,00 \\
\hline Avaliação & 14 & 100,00 \\
\hline Créditos & 13 & 92,86 \\
\hline Bibliografia - livros & 13 & 92,86 \\
\hline
\end{tabular}


Universidade do Estado de Santa Catarina

Centro de Educação Superior do Alto Vale do Itajaí

\begin{tabular}{l|c|c}
\hline Atividades presenciais e não presenciais & 13 & 92,86 \\
\hline Professor /contato & 13 & 92,86 \\
\hline Conteúdo Programático & 13 & 92,86 \\
\hline Metodologia de ensino & 12 & 85,71 \\
\hline Pré-requisitos (essenciais e recomendáveis) & 10 & 71,43 \\
\hline Horário das aulas & 9 & 64,29 \\
\hline Cronograma das aulas & 7 & 50,00 \\
\hline \multicolumn{2}{c}{ Fonte: elaborada pelos autores }
\end{tabular}

Todos os Planos mencionaram os "objetivos da disciplina", as "competências" a serem adquiridas pelos alunos e a forma de "avaliação" da disciplina. Em 13 planos são citados a quantidade de "créditos" da disciplina, as "bibliografias-livros" básicas ou sugeridas, as "Atividades presenciais e não presenciais", o "nome e/ou contato do professor" e o "conteúdo programático". A metodologia foi encontrada em 12 planos. Os "pré-requisitos" constam em 10 planos e nem sempre aparecem como essenciais, mas sim recomendáveis. O "horário das aulas" presenciais e não presenciais está em 9 dos planos, que listam também os horários das tutorias. O "cronograma das aulas" consta em 50\% dos Planos de Ensino analisados.

\subsection{Elemento do Plano de Ensino "Avaliação"}

O elemento curricular "Avaliação" teve os métodos de avaliação mencionados nos currículos das universidades pesquisadas conforme disposto na Tabela 3.

Tabela 3 - Métodos de avaliação utilizados nos planos de ensino

\begin{tabular}{l|c|c}
\hline Métodos de Avaliação & N. de Menções & (\%) \\
\hline Prova final/exame final & 14 & 100,00 \\
\hline Provas parciais/ exames intermediários & 10 & 71,43 \\
\hline Trabalhos individuais , exercícios, problemas & 9 & 64,29 \\
\hline Participação & 7 & 50,00 \\
\hline Trabalhos em grupo/Casos práticos em grupo & 5 & 35,71 \\
\hline Seminário & 1 & 7,14 \\
\hline Exame oral & 1 & 7,14 \\
\hline
\end{tabular}

Fonte: elaborada pelos autores

De acordo com os Planos de ensino analisados, todos realizam uma Prova ou Exame final como instrumento de avaliação em conjunto com outros métodos e critérios como "Provas parciais" ou "Exames intermediários" (mencionado em 10 Planos), assim como "Trabalhos individuais", "exercícios e problemas", citado em 9 Planos. A "participação em classe" é mencionada em 50\% dos Planos, seguido pelos "Trabalhos em grupo" citado em 5 deles. Também os trabalhos em grupo e casos práticos aparecem com 5 menções nos Planos de Ensino.

\subsection{Elemento do Plano de Ensino "Conteúdo Programático"}

O assunto mais citado nos planos de ensino foi de Conceptos Básicos/Fundamentales de Costes, citado em 13 planos de ensino. Seguido de Costes pro Procesos, citado em 9, como pode-se observar na Tabela 4.

Também aparecem os assuntos: Costes Estándares, Los Centros de Costes / Centros o areas de Responsabilidad, Los Sistemas de Costes Basados en las Actividades - ABC, El coste completo o de absorción e Asignación de costes citados em 6 planos de ensino. 
Os tópicos: Presupuestos, Costes Variables y Costes Fijos Costes Directos y Costes Indirectos e El Análisis Coste-Volumen-Beneficio $(C-B-V)$ aparecem em 5 citações. Já Costes por Órdenes de Trabajo e La Contabilidad de Gestión tiveram 4, Fijación de Precios teve 3 e Gestión de Inventarios e Costes diferenciales y costes relevantes apenas 2 menções nos Planos de Ensino analisados.

Tabela 4 - Principais conteúdos citados nos planos de ensino

\begin{tabular}{l|c}
\hline Assunto & N. de Menções \\
\hline Conceptos basicos/fundamentales & 13 \\
\hline Costes por Procesos & 9 \\
\hline Costes Estándares & 6 \\
\hline Los Centros de Costes / Centros o areas de Responsabilidad & 6 \\
\hline Los Sistemas de Costes Basados en las Actividades - ABC & 6 \\
\hline El coste completo o de absorción & 6 \\
\hline Asignación de costes & 6 \\
\hline Presupuestos & 5 \\
\hline Costes Variables y Costes Fijos & 5 \\
\hline Costes Directos y Costes Indirectos & 5 \\
\hline El Análisis Coste-Volumen-Beneficio $(C-B$-V) & 5 \\
\hline Costes por Órdenes de Trabajo & 4 \\
\hline La Contabilidad de Gestión & 4 \\
\hline Fijación de Precios & 3 \\
\hline Gestión de inventarios & 2 \\
\hline Costes diferenciales y costes relevantes & 2 \\
\hline \multicolumn{1}{|c|}{ Fonte: elaborada pelos autores } & \\
\hline
\end{tabular}

Além dos assuntos constantes na Tabela 4, aparecem na pesquisa outros tópicos com apenas uma citação, como Precio de Transferencia, Just-in-Time, etc.

\subsection{Bibliografias utilizadas nos Planos de Ensino}

As bibliografias encontradas nos Planos de Ensino estão relacionadas na Tabela 5 em ordem decrescente de menções:

Tabela 5 - Bibliografia básica e sugerida nos Planos de Ensino

\begin{tabular}{l|c}
\hline Bibliografia & $\begin{array}{c}\text { N. de } \\
\text { Menções }\end{array}$ \\
\hline $\begin{array}{l}\text { Horngren, C.T., Forster, G. y Datar, S.M. (2007), Contabilidad de costos. Um enfoque gerencial } \\
\text { (12 edición). Prentice-Hall Hispanoamericana, }\end{array}$ & 9 \\
\hline $\begin{array}{l}\text { Blanco, I, Aibar, B. y Rios, S. (2001): Contabilidad de costes: cuestiones, supuestos prácticos } \\
\text { resueltos y propuesto. Madrid: Prentice Hall. }\end{array}$ & 6 \\
\hline $\begin{array}{l}\text { López, G. E., Mendaña Cuervo, C. y Rodrigues Fernández, M. A. (1998): Ejercicios de } \\
\text { contabilidad de costes y de gestión, Pirámide, Madrid. }\end{array}$ & 5 \\
\hline \begin{tabular}{l} 
Mallo, C. y Jimenez, M.A. (2009). Contabilidad de Costes. 3a Edición. Editorial Pirámide. \\
\hline
\end{tabular} & 5 \\
\hline
\end{tabular}




\begin{tabular}{|c|c|}
\hline $\begin{array}{l}\text { Álvarez-Dardet, M.C. y Gutierrez, F. (coords.) (2010): Contabilidad de Gestión. Cálculo de } \\
\text { Costes. Editorial Pirámide. }\end{array}$ & 4 \\
\hline $\begin{array}{l}\text { Alvarez Lopez, J. y Otros (2001). Introducción a la Contabilidad de Gestión:Cálculo de costes. } \\
\text { Ediciones McGraw-Hill-AECA, } 2001 .\end{array}$ & 4 \\
\hline $\begin{array}{l}\text { Fernández Fernández, A., Gutiérrez Díaz, J. y Donoso Anes, R. (1993): Contabilidad de costes y } \\
\text { contabilidad de gestión. Madrid: McGraw-Hill. }\end{array}$ & 3 \\
\hline AECA, Documentos de Principios de Contabilidad de Gestión, $n^{\circ} 0$ a 36. Ediciones & 3 \\
\hline Amat Salas, O. y Soldevila, P. (2009), Contabilidad y Gestión de Costes. SCCIDProfit, Barcelona & 3 \\
\hline $\begin{array}{l}\text { Donoso, R., Donoso, A. y Rueda, J.A. (2002) :Contabilidad Analítica: Cálculo de Costes y } \\
\text { análisis de resultados (casos }\end{array}$ & 3 \\
\hline $\begin{array}{l}\text { Muñoz, C.I., Zornoza, B.J y Veuthey, M.E; (2008) Introducción a la contabilidad de costes para } \\
\text { la gestión. } 3^{\mathrm{a}} \text { edición. Ed. Thomson Civitas }\end{array}$ & 3 \\
\hline $\begin{array}{l}\text { Sáez Torrecilla, A., Fernández Fernández, A. y Gutiérrez Díaz, G. (2004): Contabilidad de costes } \\
\text { ycontabilidad de gestión, (Volumen I y II), Mc Graw-Hill, Madrid. }\end{array}$ & 3 \\
\hline $\begin{array}{l}\text { Serra Salvador, V. CONTABILIDAD DE COSTES. (2003). Cálculo, análisis y control. Tirant Lo } \\
\text { Blanch, colección Manuales. }\end{array}$ & 3 \\
\hline $\begin{array}{l}\text { Tejada, A., Pérez, R. y Nuñez, M. (2004): Contabilidad de Costes. Supuestos prácticos. Ed. } \\
\text { Prentice Hall }\end{array}$ & 3 \\
\hline $\begin{array}{l}\text { García Suárez, J. L. (Coord), Arias Álvarez, A. M., García Cornejo, B.,Machado Cabezas, A. y } \\
\text { Pérez Méndez, J. A. (2010): Cálculo, Análisis y Gestión de Costes. Guía práctica para su } \\
\text { aplicación en la empresa, Ediciones Delta, Madrid. }\end{array}$ & 2 \\
\hline García, J. L. (2009): Cálculo, Análisis y Gestión de Costes. Delta Publicaciones, Madrid. & 2 \\
\hline $\begin{array}{l}\text { García, M. (1984): Economía de la producción y Contabilidad de costes. Instituto de Planificación } \\
\text { Contable, Madrid. }\end{array}$ & 2 \\
\hline Mallo y Kaplan. Contabilidad de Costes y Estratégica de Gestión, Prentice Hall. & 2 \\
\hline $\begin{array}{l}\text { Prieto, B.; Santidrián, A. y Aguilar, P. (2005): Contabilidad de Costes y de gestión: un enfoque } \\
\text { práctico, Ediciones Delta, Madrid }\end{array}$ & 2 \\
\hline $\begin{array}{l}\text { Requena Rodríguez, J. Ma } \text {. y Vera Ríos, S. (2008): Contabilidad interna (Contabilidad de costes y } \\
\text { de gestión). Cálculo, análisis y control de costes y resultados para la toma de decisiones ( } 3^{\mathrm{a}} \\
\text { edición). Ariel Economía, Barcelona. }\end{array}$ & 2 \\
\hline $\begin{array}{l}\text { Ripoll, V. M. y Balada, T. J. (2005): Información de costes para la tomade decisiones } \\
\text { empresariales, Ediciones Gestión } 2000 .\end{array}$ & 2 \\
\hline $\begin{array}{l}\text { Ripoll, V. M. y Otros (1993). Introducción a la Contabilidad de Gestión. Cálculo de Costes. Ed. } \\
\text { McGraw Hill, Madrid. }\end{array}$ & 2 \\
\hline $\begin{array}{l}\text { Rosanas, J. y Ballarín, E. (1990): Contabilidad de costes para la toma de decisiones, Ed. Desclee } \\
\text { de Brouwer. }\end{array}$ & 2 \\
\hline Outras bibliografias citadas & 1 \\
\hline
\end{tabular}
Fonte: elaborada pelos autores

A bibliografia mais citada é a obra Contabilidad de Costos dos autores Horngren, Foster e Datar, mencionada em 9 dos Planos de Ensino. Seguido dos autores Blanco, Aibar, e Rios, com a obra Contabilidad de Costes: cuestiones, supuestos prácticos resueltos y propuesto e 6 menções. Em terceiro lugar, as obras Ejercicios de contabilidad de costes y de gestión dos autores López, 
Mendaña Cuervo e Rodrigues Fernández e Contabilidad de Costes de autoria de Mallo e Jimenez, ambas com 5 menções.

\section{Considerações Finais}

O propósito da pesquisa foi o de identificar o perfil da disciplina de contabilidade de custos nos cursos de graduação oferecidos nas universidades espanholas por meio dos planos de ensino da disciplina que abordam o conteúdo de contabilidade de custos nos cursos de graduação em Contabilidade e Finanças.

Os conteúdos programáticos mais mencionados foram Conceptos Básicos/Fundamentales de Costes, seguidode Costes pro Procesos, Costes Estándares, Los Centros de Costes/Centros o areas de Responsabilidad, Los Sistemas de Costes Basados en las Actividades (ABC), El Coste Completo o de Absorción e Asignación de Costes. Também os tópicos: Presupuestos, Costes Variables y Costes Fijos Costes Directos y Costes Indirectos e El Análisis Coste-VolumenBeneficio $(C-B-V)$.

Os Planos de Ensino das Universidades da Espanha analisados demonstram certo grau de homogeneidade em sua estrutura quanto aos itens: "objetivo da disciplina"; "competências" que são divididas em básicas e específicas; "avaliação" cujo critério e ferramentas principais são as provas finais com maior peso e provas parciais ou intermediárias.

A bibliografia mais citada nos planos de ensino foi a obra Contabilidad de Costos dos autores Horngren, Foster e Datar, mencionada em 9 dos Planos de Ensino. Seguido dos autores Blanco, Aibar e Rios, com a obra "Contabilidad de Costes: cuestiones, supuestos prácticos resueltos y propuesto" e 6 menções assim como a quantidade de créditos (6) e a menção do nome e contato do professor em sala e para tutorias.

Para futuras pesquisas, sugere-se fazer um comparativo entre a estrutura da disciplina de custos abordada neste estudo com os dos cursos de graduação das universidades federais do Brasil.

\section{Referências}

ANDERSEN, B. Industrial benchmarking for competitive advantage. Human Systems Management, v. 18, issue 3-4, p. 287-29, 1999.

BORGES, M. C. A. Reforma da universidade no contexto da integração europeia: o processo de Bolonha e seus desdobramentos. Educação Social, Campinas, v. 34, 67-80, 2013.

CARRILLO, D. B. II Encuentro de docentes de contabilidad de costes y control de gestión. La Contabilidad de Costes / Contabilidad de Gestión en los estudios de Grado de la universidad pública española.Sevilla, 1-28, 2011.

DEMO, P. Avaliação e democracia. Abceducativo. São Paulo, 4 (22), 28-32, 2003.

ERFURTH, A. E. et al. O ISAR/UNCTAD, as diretrizes curriculares brasileiras e as disciplinas de Contabilidade de Custos: reflexões na área de Contabilidade. In: Congresso Brasileiro de Custos, Fortaleza. Anais... Fortaleza: UFC, 2009. 
PEREZ, B. P.; GALLARDO, A. L. P; PEÑA, C. R.. La investigación empírica en contabilidad de gestión en España: análisis de las publicaciones españolas. Revista Española de Financiación y Contabilidad, v. XXXIV 183-210, 2005.

Fundación para la proyección internacional de las universidades españolas. Disponível em: $<$ http://universidad.es/es/en-espana/estudiar-en-espana/el-sistema-universitario-espanol>. Acesso em 15 dez.2013.

GALLON, A. V.; ORO, I. M.; EIDT, J.; DOMINGUES, M. J. C. S. Disciplinas de custos: uma análise nos cursos de Ciências Contábeis das IES do sistema ACAFE. V Coloquio Internacional sobre Gestión Universitaria en América del Sur, 2005.

GARIBA JÚNIOR, M. Um modelo de avaliação de cursos superiores de tecnologia baseado na ferramenta benchmarking. Tese (Doutorado) Universidade Federal de Santa Catarina, Programa de Pós-Graduação em Engenharia de Produção 304p, 2005.

GIL, A. C. Como elaborar projetos de pesquisa. (4. ed.) São Paulo: Atlas, 2002.

GODOY, A. S.; SILVA, H. A.; NAKAMURA, W. T. Análise dos programas de ensino da área de custos no currículo dos cursos de graduação em administração de empresas. Revista Eletrônica de Administração, 10 (4), 2010.

ITOZ, C.; MINEIRO, M.. Ensino-aprendizagem da contabilidade de custos: componentes, desafios e inovação prática. Enfoque: Reflexão Contábil, 24 (2), 53- 65, 2005.

IUDÍCIBUS, S.. Teoria da contabilidade. (9. ed.) São Paulo: Atlas, 2009.

LIBÂNEO, J. C. Didática. São Paulo: Cortez, 1999.

LIBÂNEO, J. C. Organização e gestão escolar: teoria e prática. 4. ed. Goiânia: Alternativa, 2001.

LÜCK, H.. Planejamento em orientação educacional. 10. ed. Petrópolis: Vozes, 2002.

MAGAlHÂES, F. A. C.; ANDRADE, J. X. A educação contábil no Estado do Piauí diante da proposta de convergência internacional do currículo de contabilidade concebida pela ONU/Unctad/Isar. In: 6o Congresso USP de Controladoria e Contabilidade.Anais... São Paulo: USP, 2006.

MECD - Ministerio de Educaciòn, Cultura y Deporte. Disponível em: $<$ http://www.mecd.gob.es/educacion-mecd/areas-educacion/universidades/estadisticasinformes/datos-cifras.html>. Acesso em 10 jan.2014.

MECD - Ministerio de Educaciòn, Cultura y Deporte. Disponível em: $<$ http://www.mecd.gob.es/dms/mecd/educacion-mecd/areasducacion/universidades/estadisticas-informes/estadisticas-informes-documentum/datoscifras/2012-2013-datos-y-cifras-sistema-universitario-espanol>. Acesso em 10 jan.2014 
NOSSA, V.; COELHO, C. R. A.; CHAGAS, J. F. O ensino da contabilidade de custos no Brasil. Revista Brasileira de Contabilidade. 1998.

PINTO, J.; SILVEIRA, A.; DOMINGUES, M..J.C.S. Ensino de custos no curso de administração da Universidade do Oeste de Santa Catarina. In: $8^{\circ}$ Congresso USP Controladoria e Contabilidade, São Paulo-SP, 2008.

RAUPP, F. M. et al. O ensino de contabilidade de custos nos cursos de graduação em administração do Estado de Santa Catarina.Associação Brasileira de Custos, v. 4, n. 2, p. 6179, 2009.

RICCIO, E. L.; SAKATA, M. C. G. Evidências da globalização na educação contábil: estudo das grades curriculares dos cursos de graduação em universidades brasileiras e portuguesas. Revista de Contabilidade e Finanças - USP, São Paulo, 35, 35-44, 2004.

ROSA, F. S.; LUNKES, R. J.; PFITSCHER, E. D.; SOARES, S. V. Análise da legitimidade cognitiva da Contabilidade Gerencial da Espanha. In: VIII Congreso Iberoamericano de Administración Empresarial y Contabilidad, 2012, Lima-Peru. VIII Congreso Iberoamericano de Administración Empresarial y Contabilidade. Lima- Peru: Pontifícia Universidad Católica del Peru, 2012.

UNCTAD - United Nations Conference on Trade and Development.Guideline on National Requirements for the Qualification of Professional Accountants.New York/Geneve, 1999.

UNCTAD - United Nations Conference on Trade and Development. Revised Model Accounting Curriculum (MC). New York/Geneve, 2003. 